\title{
Systematic Review and Network Meta-analysis of Idiopathic Pulmonary Fibrosis Treatments
}

\author{
Kelly Fleetwood, MSc; Rachael McCool, BSc; Julie Glanville, MSc; Susan C. Edwards, PhD; \\ Sandro Gsteiger, PhD; Monica Daigl, MSc; and Mark Fisher, MSc
}

\begin{abstract}
BACKGROUND: The antifibrotics pirfenidone and nintedanib are both approved for the treatment of idiopathic pulmonary fibrosis (IPF) by regulatory agencies and are recommended by health technology assessment bodies. Other treatments such as $\mathrm{N}$-acetylcysteine are used in clinical practice but have not received regulatory approval. No head-to-head trials have been conducted to directly compare the efficacy of these therapies in IPF.

OBJECTIVE: To compare the efficacy of treatments for IPF.

METHODS: A systematic review was conducted up to April 2015. Phase II/ III randomized controlled trials in adults with IPF were eligible. A Bayesian network meta-analysis (NMA) was used to compare pirfenidone, nintedanib, and $\mathrm{N}$-acetylcysteine with respect to forced vital capacity (FVC) and mortality.

RESULTS: Nine studies were included in the NMA. For change from baseline in FVC, the NMA indicated that pirfenidone and nintedanib were more effective than placebo after 1 year (pirfenidone vs. placebo: difference $=0.12$ liter $(\mathrm{L}), 95 \%$ credible interval $[\mathrm{Crl}]=0.03-0.21 \mathrm{~L}$; nintedanib vs. placebo: difference $=0.11 \mathrm{~L}, 95 \% \mathrm{Crl}=0.00-0.22 \mathrm{~L}$ ). There was no evidence that $\mathrm{N}$-acetylcysteine had an effect on FVC compared with placebo ( $\mathrm{N}$-acetylcysteine vs. placebo: difference $=0.01 \mathrm{~L}, 95 \% \mathrm{Crl}=-0.15-0.17 \mathrm{~L}$ ). Patients treated with pirfenidone also had a lower risk of experiencing a decline in percent predicted FVC of $\geq 10 \%$ over 1 year (odds ratio [OR]: $0.58,95 \% \mathrm{Crl}=0.40-0.88$ ), whereas there was no conclusive evidence of a difference between nintedanib and placebo (OR: 0.65, 95\% $\mathrm{Crl}=0.42-1.02$ ). The NMA indicated that pirfenidone reduced all-cause mortality relative to placebo over 1 year (hazard ratio [HR]: $0.52,95 \% \mathrm{Crl}=0.28-0.92$ ). There was no evidence of a difference in all-cause mortality between nintedanib and placebo (HR: $0.70,95 \% \mathrm{Crl}=0.32-1.55$ ), or $\mathrm{N}$-acetylcysteine and placebo (HR: $2.00,95 \% \mathrm{Crl}=0.46-8.62$ ).
\end{abstract}

CONCLUSIONS: Our primary analysis of the available evidence indicates that over 1 year, pirfenidone and nintedanib are effective at reducing lungfunction decline, and pirfenidone may reduce the odds of experiencing a decline in percent predicted FVC of $\geq 10 \%$ compared with placebo in the first year of treatment. The results of our analysis also suggest that pirfenidone improves survival.

J Manag Care Spec Pharm. 2017;23(3-b):S5-S16.

Copyright $\odot 2017$, Academy of Managed Care Pharmacy. All rights reserved.

I diopathic pulmonary fibrosis (IPF) is a rare disease, designated as an orphan indication by the European Medicines Agency (EMA). ${ }^{1}$ It is a life-threatening disorder, characterized by progressive fibrosis of the interstitium of the lung, decreased lung volume, and pulmonary insufficiency, typically leading to death within 2-5 years. ${ }^{2}$ The treatment goal is to stabilize the disease if possible or, at least, to reduce the rate of progression. ${ }^{3}$

The cause of IPF is unknown, but it appears likely to arise from the interplay between environmental and genetic factors. Cigarette smoking is the most consistent environmental risk factor. Gene mutations and polymorphisms have been shown in both sporadic IPF and familial pulmonary fibrosis. Other potential risk factors include chronic viral infection and gastroesophageal reflux. ${ }^{4}$

Current recommended treatments for IPF are pirfenidone and nintedanib, ${ }^{5}$ which were licensed for the treatment of IPF by the EMA in 2011 and 2015, respectively, ${ }^{1,6}$ and by the U.S. Food and Drug Administration (FDA) in 2014.,8 Pirfenidone and nintedanib have also been recommended by health technology assessment bodies, including the National Institute for Health and Care Excellence (NICE) in England ${ }^{9}$ and the Scottish Medicines Consortium (SMC). ${ }^{10,11}$ N-acetylcysteine and triple therapy ( $\mathrm{N}$-acetylcysteine, prednisolone, and azathioprine) are not recommended but are still used in clinical practice. ${ }^{5,12}$ Patients with IPF may also receive pulmonary rehabilitation and/or oxygen therapy as part of best supportive care, which is a therapeutic approach prioritizing symptom management. ${ }^{13}$

The comparative effectiveness of these treatments for IPF requires further investigation. Hence, a systematic review (SR) and a network meta-analysis (NMA) of the available evidence were conducted to provide a thorough assessment of the impact of these treatments on forced vital capacity (FVC) and mortality. Conducting an NMA allows for the use of indirect comparisons; i.e., data from studies that did not directly compare the treatments of interest. A standard meta-analysis (MA) would have been restricted to using direct comparisons between treatments from head-to-head trials of IPF treatments, which have not been conducted.

Although several other MAs and NMAs, including a number of technology assessments, ,10,11,14-25 have recently investigated treatments for IPF, our NMA is the first to include 1-year data from the CAPACITY trials, ${ }^{26}$ which has enabled us to combine data from similar time points across all studies included. This is in contrast to previous NMAs, which have combined data from different time points, thus assuming that the treatment effect does not change over time, which is known not to be the case. ${ }^{27}$ Additional FVC results from the CAPACITY studies and ASCEND have allowed us to conduct a thorough assessment of the effect of the treatments on change from baseline in FVC. The design of our NMA is therefore novel and holds a key differential advantage over previous analyses.

\section{Methods}

We conducted an SR of the treatment options for IPF and performed an NMA. The SR was informed by a protocol developed a priori. Eligible studies were Phase II and III randomized controlled trials (RCTs), published in English, reporting the 


\section{FIGURE 1 PRISMA Flow Diagram}

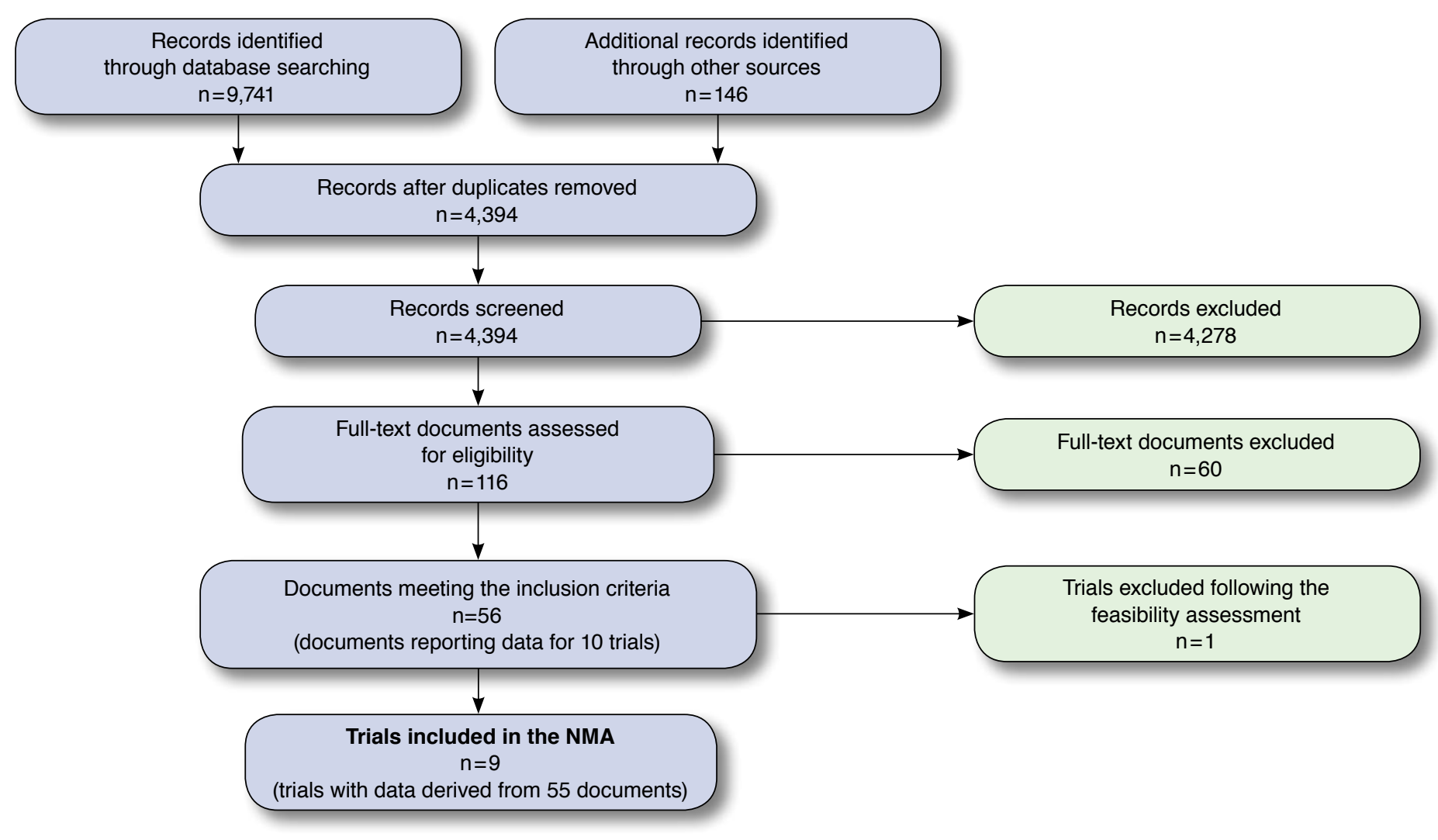

Note: Excluded studies and the 55 included studies are listed in Appendix B.

NMA = network meta-analysis.

effectiveness of pirfenidone, nintedanib, N-acetylcysteine, or triple therapy used to treat individuals aged $\geq 18$ years with suspected or diagnosed IPF. Pirfenidone, nintedanib, $\mathrm{N}$-acetylcysteine, and triple therapy were considered the most relevant treatment options based on registry evidence showing that these treatments are used in clinical practice. ${ }^{12,28}$ $\mathrm{N}$-acetylcysteine alone, although not recommended in the clinical guidelines, ${ }^{5}$ is still used in some patients on the basis of clinical opinion, particularly for symptom relief. ${ }^{12}$ Triple therapy now has a strong recommendation against use in new patients, although a small minority of patients who have remained stable on this treatment regimen continue to take the treatment at the discretion of their treating physicians. ${ }^{5,12}$

A number of outcomes were considered in the NMA, including change in FVC (volume measured in liters [L] and percent predicted); categorical declines in percent predicted FVC; change in 6-minute walking distance (6MWD); change in health-related quality of life; all-cause mortality; IPF-related mortality; progression-free survival (PFS); acute exacerbations; all-cause discontinuation of study; and all-cause discontinuation of treatment. For the purposes of this SR, FVC and vital capacity were assumed to be similar measurements in patients with IPF. ${ }^{29}$

Systematic literature searches were conducted in October 2011, and updated searches were performed in April 2015. Searches were conducted in databases (MEDLINE, EMBASE, the Cochrane Library, and PubMed), conference proceedings, and a previous SR. The search strategy was designed to search for the concepts of (IPF and RCTs) or pirfenidone to maximize search sensitivity in identifying RCTs in IPF (Appendix A). The search results were assessed for relevance according to the SR eligibility criteria, with records screened in several stages (Figure 1). Studies were selected by 2 independent reviewers. Any differences in decisions were resolved through discussion and/or by consulting another reviewer. Studies excluded after examination of the full text are listed, along with the reason for their exclusion, in Appendix B. 
Data were extracted from the studies to facilitate an assessment of suitability for comparison of trials in an NMA. Data were collected on key study characteristics, including study methods, populations, trial settings, treatments, and outcomes. One reviewer extracted key study characteristics using a standardized data extraction form, and a second reviewer checked each extraction. Any discrepancies were resolved by discussion or with the input of a third reviewer. The similarity of the candidate studies was assessed using a modified version of the tool developed by the Australian Pharmaceutical Benefits Advisory Committee $^{30}$ (Appendix C).

The risk of bias in the RCTs was assessed using the quality assessment approach suggested in the NICE single technology appraisal (STA) guidance, ${ }^{31}$ which is very similar to the Cochrane risk of bias tool. For the purposes of this review, a study was assumed to have a "low risk" of bias when all of the key quality criteria (i.e., randomization method, allocation concealment, and blinding) were adequately met, an "unclear risk" of bias when key criteria were not reported or were unclear, and a "high risk" of bias when 1 or more of the key criteria were not adequately met.

Two networks were developed, taking into account the similarity of the trials, outcome measures, and the data available in each trial. The base-case network included Phase III RCTs of pirfenidone, nintedanib, and N-acetylcysteine, while the extended network also included Phase II RCTs and trials of triple therapy.

For each outcome, the principal analysis used was a Bayesian random effects (RE) model applied to data at approximately 52 weeks from the base-case network. For change from baseline outcomes, the results were summarized as mean differences between treatments, and for binary outcomes, the results were summarized as odds ratios (ORs). For all-cause mortality, the principal analysis was based on hazard ratios (HRs) using data up to 52 weeks, with 1 sensitivity analysis also based on HRs but using data up to 72 weeks and another sensitivity analysis based on ORs at approximately 52 weeks. For survival outcomes, HRs are more informative than ORs because they account for the time to death, rather than simply whether death has occurred by a specific time point.

For further details on the choice of outcome measures and the statistical methodology, see Appendix D. All results are summarized by point estimates and their $95 \%$ credible intervals (CrIs).

For each outcome, 4 sensitivity analyses were conducted to explore whether the network and type of model influenced the conclusions:

1. Base-case network, Bayesian fixed effect (FE) model

2. Base-case network, Bayesian RE model (alternative prior distribution for the between-study variance)

3. Extended network, Bayesian RE model

4. Extended network, Bayesian FE model
Further details on the statistical methods and the sensitivity analyses are provided in Appendix D.

Instances of heterogeneity in the study characteristics or outcome measures were highlighted, and a clinical perspective was obtained on whether the differences between studies warranted their exclusion from the analysis. In addition to this qualitative assessment of heterogeneity in the study characteristics and outcome measures, a quantitative assessment of heterogeneity was also undertaken to evaluate the variability in results from study to study. For each outcome, statistical heterogeneity was evaluated for each pairwise comparison that was informed by at least 2 trials. Statistical heterogeneity was quantified using the I-squared statistic. ${ }^{32}$ I-squared values of $25 \%, 50 \%$, and $75 \%$ were defined as low, moderate, and high heterogeneity, respectively. 32

\section{Results}

The searches identified a total of 9,887 records. One hundred sixteen full-text reports were assessed and 56 documents, reporting data for 10 trials, met the eligibility criteria (Figure 1). Eight Phase III trials (ASCEND, CAPACITY 1 and 2, INPULSIS 1 and 2, SP3, PANTHER, and IFIGENIA ${ }^{26,33-38}$ ) and 2 Phase II trials (SP2 and TOMORROW ${ }^{39,40}$ ) were identified for consideration within the NMA. Five trials compared pirfenidone with placebo, 3 trials compared nintedanib with placebo, 1 trial compared $\mathrm{N}$-acetylcysteine and triple therapy with placebo, and 1 trial compared double therapy with triple therapy. Key characteristics of the eligible studies are presented in Table 1. The IFIGENIA trial, ${ }^{35}$ comparing double therapy with triple therapy, was excluded from the NMA because it would not have contributed any information to the comparisons of interest in the network. The network (Figure 2) was also limited to study arms investigating the approved doses of pirfenidone and nintedanib (pirfenidone 1,800 or $2,403 \mathrm{mg} /$ day and nintedanib $300 \mathrm{mg} / \mathrm{day})$.

Data were collected from each trial to assess the similarity of studies for inclusion in an NMA and the availability of data for each of the outcomes of interest. Dosing differences for pirfenidone were noted between the Japanese trials (1,800 and $1,200 \mathrm{mg} / \mathrm{day})^{33,39}$ and those conducted in the rest of the world $\left(2,403\right.$ and $1,197 \mathrm{mg} /$ day). ${ }^{26,34}$ These differences in dosage reflect the difference in mean weights in the North American and European populations compared with the Japanese population, and the doses have previously been deemed comparable. ${ }^{41}$

The studies varied in terms of study length and the time point at which outcomes were measured. The treatment duration varied from an average of 32 weeks (PANTHER triple therapy $\mathrm{arm}^{37}$ ) to 72 weeks (CAPACITY trials ${ }^{26}$ ), with the majority of trials reporting data at 52 weeks.

ASCEND, SP3, INPULSIS 1, and INPULSIS 2 all reported data at approximately 52 weeks. ${ }^{33,34,38}$ Although the primary endpoint for the CAPACITY trials was 72 weeks, outcome 


\begin{tabular}{|c|c|c|c|c|c|c|c|}
\hline Trial & Study Design & Location & Date of Trial & $\begin{array}{c}\text { Duration of } \\
\text { Treatment }\end{array}$ & Study Arms & $\begin{array}{c}\text { Number of } \\
\text { Patients }\end{array}$ & $\begin{array}{c}\text { Baseline } \\
\text { Mean FVC, } \\
\% \text { (SD) }\end{array}$ \\
\hline \multirow[t]{2}{*}{ CAPACITY $1^{26}$} & \multirow{2}{*}{$\begin{array}{c}\text { Phase III; randomized, } \\
\text { double-blind, placebo- } \\
\text { controlled trial }\end{array}$} & \multirow[t]{2}{*}{$\begin{array}{l}110 \text { centers in Australia, } \\
\text { Europe, and North America }\end{array}$} & \multirow[t]{2}{*}{$\begin{array}{l}\text { Apr 2006- } \\
\text { Nov } 2008\end{array}$} & \multirow[t]{2}{*}{72 weeks } & $\begin{array}{c}\text { Pirfenidone } \\
(2,403 \mathrm{mg} / \text { day })\end{array}$ & 171 & $74.9(13.2)$ \\
\hline & & & & & Placebo & 173 & $73.1(14.2)$ \\
\hline \multirow[t]{3}{*}{ CAPACITY $2^{26}$} & \multirow{3}{*}{$\begin{array}{l}\text { Phase III; randomized, } \\
\text { double-blind, placebo- } \\
\text { controlled trial }\end{array}$} & \multirow[t]{3}{*}{$\begin{array}{l}110 \text { centers in Australia, } \\
\text { Europe, and North America }\end{array}$} & \multirow[t]{3}{*}{$\begin{array}{l}\text { Jun 2006- } \\
\text { Nov } 2008\end{array}$} & \multirow[t]{3}{*}{72 weeks } & $\begin{array}{c}\text { Pirfenidone } \\
(2,403 \mathrm{mg} / \text { day })\end{array}$ & 174 & $74.5(14.5)$ \\
\hline & & & & & $\begin{array}{c}\text { Pirfenidone } \\
(1,197 \mathrm{mg} / \text { day })\end{array}$ & 87 & $76.4(14.4)$ \\
\hline & & & & & Placebo & 174 & $76.2(15.5)$ \\
\hline \multirow[t]{2}{*}{$\mathrm{SP} 2^{39}$} & \multirow{2}{*}{$\begin{array}{l}\text { Phase II; randomized, } \\
\text { double-blind, placebo- } \\
\text { controlled trial }\end{array}$} & \multirow[t]{2}{*}{25 sites in Japan } & \multirow[t]{2}{*}{$\begin{array}{l}\text { Nov } 2000- \\
\text { Jan } 2001\end{array}$} & \multirow[t]{2}{*}{36 weeks } & $\begin{array}{c}\text { Pirfenidone } \\
(1,800 \mathrm{mg} / \text { day })\end{array}$ & 73 & $81.6(20.3)$ \\
\hline & & & & & Placebo & 36 & $78.4(17.2)$ \\
\hline \multirow[t]{3}{*}{ SP333 } & \multirow{3}{*}{$\begin{array}{l}\text { Phase III; randomized, } \\
\text { double-blind, placebo- } \\
\text { controlled trial }\end{array}$} & \multirow[t]{3}{*}{73 centers in Japan } & \multirow[t]{3}{*}{$\begin{array}{l}\text { Jul 2004- } \\
\text { Aug } 2005\end{array}$} & \multirow[t]{3}{*}{52 weeks } & $\begin{array}{c}\text { Pirfenidone } \\
(1,800 \mathrm{mg} / \text { day })\end{array}$ & 110 & $77.3(16.8)$ \\
\hline & & & & & $\begin{array}{c}\text { Pirfenidone } \\
(1,200 \mathrm{mg} / \text { day })\end{array}$ & 56 & $76.2(18.7)$ \\
\hline & & & & & Placebo & 109 & $79.1(17.4)$ \\
\hline \multirow[t]{2}{*}{$\mathrm{ASCEND}^{34}$} & \multirow{2}{*}{$\begin{array}{l}\text { Phase III; randomized, } \\
\text { double-blind, placebo- } \\
\text { controlled trial }\end{array}$} & \multirow{2}{*}{$\begin{array}{l}127 \text { sites in } 9 \text { countries (11 } \\
\text { sites in Australia, } 6 \text { in Brazil, } \\
2 \text { in Croatia, } 5 \text { in Israel, } 5 \text { in } \\
\text { Mexico, } 2 \text { in New Zealand, } 8 \\
\text { in Peru, } 1 \text { in Singapore, and } \\
87 \text { in the United States) }\end{array}$} & \multirow[t]{2}{*}{$\begin{array}{l}\text { Jun 2011- } \\
\text { Feb } 2014\end{array}$} & \multirow[t]{2}{*}{52 weeks } & $\begin{array}{c}\text { Pirfenidone } \\
(2,403 \mathrm{mg} / \text { day })\end{array}$ & 278 & $67.8(11.2)$ \\
\hline & & & & & Placebo & 277 & $68.6(10.9)$ \\
\hline \multirow[t]{5}{*}{ TOMORROW ${ }^{40}$} & \multirow{5}{*}{$\begin{array}{l}\text { Phase II; randomized, } \\
\text { double-blind, placebo- } \\
\text { controlled trial }\end{array}$} & \multirow[t]{5}{*}{92 sites in 25 countries } & \multirow[t]{5}{*}{$\begin{array}{l}\text { Sep } 2007- \\
\text { Jun } 2010\end{array}$} & \multirow[t]{5}{*}{52 weeks } & $\begin{array}{l}\text { Nintedanib } \\
150 \mathrm{mg} \text { BID }\end{array}$ & 86 & $78.1^{\mathrm{a}}$ \\
\hline & & & & & $\begin{array}{l}\text { Nintedanib } \\
100 \mathrm{mg} \text { BID }\end{array}$ & 86 & $83.0^{a}$ \\
\hline & & & & & Nintedanib $100 \mathrm{mg}$ & 86 & $80.4^{a}$ \\
\hline & & & & & Nintedanib $50 \mathrm{mg}$ & 85 & $79.8^{a}$ \\
\hline & & & & & Placebo & 85 & $77.6^{\mathrm{a}}$ \\
\hline \multirow[t]{2}{*}{ INPULSIS $1^{38}$} & $\begin{array}{l}\text { Phase III; double-blind, } \\
\text { randomized, placebo- }\end{array}$ & $\begin{array}{l}98 \text { study locations in } \\
\text { Australia, Belgium, China, }\end{array}$ & $\begin{array}{l}\text { Apr 2011- } \\
\text { Oct } 2013\end{array}$ & 52 weeks & $\begin{array}{l}\text { Nintedanib } \\
150 \mathrm{mg} \text { BID }\end{array}$ & 309 & $79.5(17.0)$ \\
\hline & & $\begin{array}{l}\text { Czech Republic, France, } \\
\text { Germany, India, Ireland, } \\
\text { Israel, Italy, Japan, United } \\
\text { Kingdom, United States }\end{array}$ & & & Placebo & 204 & $80.5(17.3)$ \\
\hline INPULSIS $2^{38}$ & $\begin{array}{l}\text { Phase III; double-blind, } \\
\text { randomized, placebo- }\end{array}$ & $\begin{array}{l}108 \text { study locations in } \\
\text { Canada, Chile, China, }\end{array}$ & $\begin{array}{c}\text { May } 2011- \\
\text { Oct } 2013\end{array}$ & 52 weeks & $\begin{array}{l}\text { Nintedanib } \\
150 \mathrm{mg} \text { BID }\end{array}$ & 329 & $80.0(18.1)$ \\
\hline & controlled trial & $\begin{array}{l}\text { Finland, France, Germany, } \\
\text { Greece, India, Japan, } \\
\text { Republic of Korea, Mexico, } \\
\text { the Netherlands, Portugal, } \\
\text { Russian Federation, Spain, } \\
\text { Turkey, United States }\end{array}$ & & & Placebo & 219 & $78.1(19.0)$ \\
\hline PANTHER 36,37 & $\begin{array}{c}\text { Phase III; randomized, } \\
\text { double-blind, placebo- } \\
\text { controlled trial }\end{array}$ & $\begin{array}{l}25 \text { clinical centers in the } \\
\text { United States }\end{array}$ & $\begin{array}{l}\text { Dec 2009- } \\
\text { mid-Oct 2011 } \\
\text { (before the }\end{array}$ & $\begin{array}{c}60 \text { weeks } \\
\text { planned (triple } \\
\text { therapy arm }\end{array}$ & $\begin{array}{c}\text { Prednisone, } \\
\text { azathioprine +NAC } \\
\text { (600 mg TID) }\end{array}$ & 77 & $69.3(15.1)$ \\
\hline & & & clinical alert) & & Placebo & 78 & $72.1(14.4)$ \\
\hline & & & & & NAC (600 mg TID) & 133 & $72.2(15.9)$ \\
\hline & & & $\begin{array}{c}\text { (after the } \\
\text { clinical alert) }\end{array}$ & $\begin{array}{c}\text { follow-up } 32 \\
\text { weeks) }\end{array}$ & Placebo & 131 & $73.4(14.3)$ \\
\hline IFIGENIA $^{35}$ & $\begin{array}{l}\text { Phase III; double-blind, } \\
\text { randomized, placebo- } \\
\text { controlled trial }\end{array}$ & $\begin{array}{c}36 \text { centers in } 6 \text { European } \\
\text { countries }\end{array}$ & $\begin{array}{c}\text { Mar } 2000- \\
\text { Jul } 2002\end{array}$ & 52 weeks & $\begin{array}{c}\text { Prednisone, } \\
\text { azathioprine + NAC } \\
(600 \mathrm{mg} \text { TID })\end{array}$ & 80 & $62.1(13.9)$ \\
\hline & & & & & $\begin{array}{l}\text { Prednisone, } \\
\text { azathioprine }\end{array}$ & 75 & $61.6(11.5)$ \\
\hline
\end{tabular}




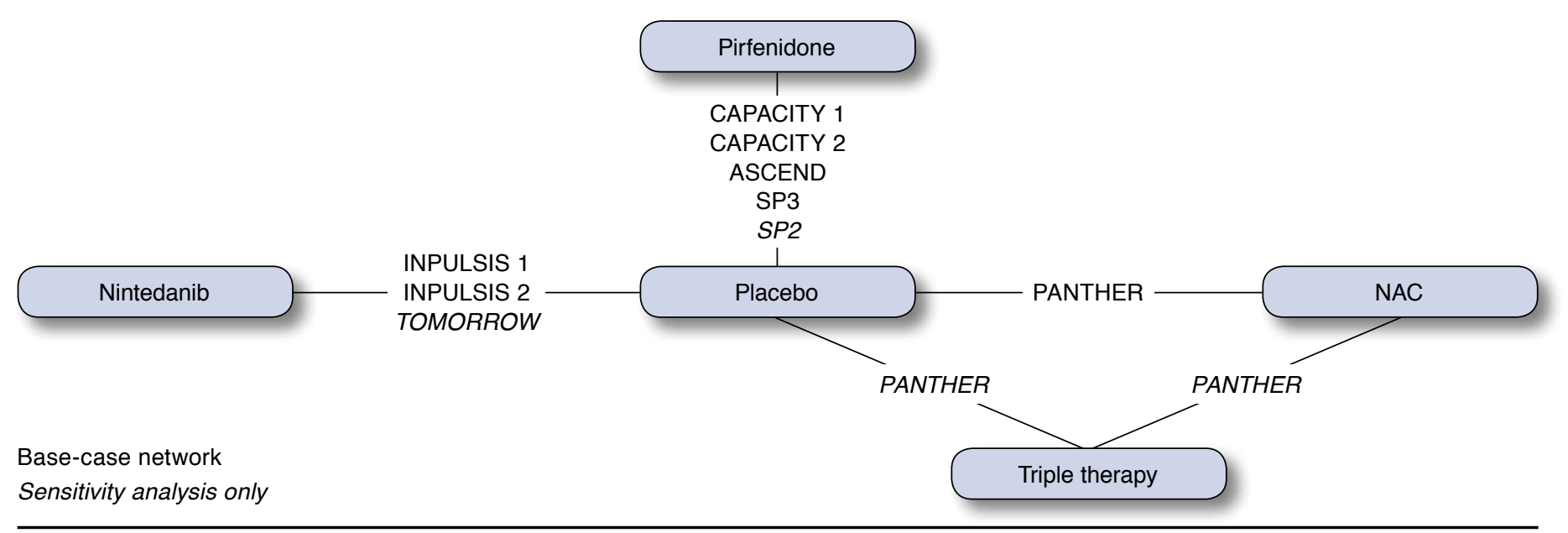

Note: Treatments are presented as nodes, and studies provide the links between nodes. The names of studies contributing to each link between nodes are listed on the corresponding link.

NAC $=$ N-acetylcysteine

data were obtained from F. Hoffmann-La Roche. (Basel, Switzerland) at 48 weeks for continuous outcomes and at 52 weeks for survival outcomes, to facilitate the analysis of data at similar time points. Data for $\mathrm{N}$-acetylcysteine versus placebo in the PANTHER trial were available at 60 weeks. ${ }^{36}$

The trials used different methods for handling missing FVC data. In the CAPACITY and ASCEND trials, missing values as a result of death were assigned the worst possible value (e.g., FVC $=0$ ). ${ }^{26,34}$ Missing data for reasons other than death were imputed for each patient using the average value from the trials' 3 closest patients for whom measurements were available. Closest patients were selected using the smallest sum of squared differences over all available measurements before the missing visit. For FVC outcomes included in this review, SP2, SP3, and TOMORROW applied the last observation carriedforward approach when data for the entire 52-week period were not available. ${ }^{33,39,40}$ In the INPULSIS trials, missing values for continuous endpoints were not imputed; missing values for categorical endpoints were assigned the worst result. ${ }^{38}$

Rates of discontinuation and loss to follow-up also varied between the trials. In the CAPACITY and ASCEND trials, $14 \%-20 \%$ of patients in the treatment groups discontinued study medication, and between $4.6 \%$ and $7.5 \%$ of patients were lost to follow-up. ${ }^{26,34}$ In the INPULSIS trials, $17 \%-25 \%$ of patients discontinued study medication and 12\%-22\% of patients were lost to follow-up. ${ }^{38}$ Between $22 \%$ and $37 \%$ of patients in SP2 and SP333,39 and 15\% and 17\% of patients in the PANTHER trial (N-acetylcysteine and placebo arms) discontinued study medication, but it is unclear whether these patients were considered lost to follow-up. ${ }^{36}$ Between $16 \%$ and $38 \%$ of patients across the treatment arms in the TOMORROW trial discontinued study medication early, but the authors reported that data at the planned end of treatment were available for $94.3 \%$ of patients in the placebo group and for $93.1 \%-97.7 \%$ of patients in the 4 treatment groups. ${ }^{40}$

Not all of the eligible studies were completed; SP2, a Phase II trial comparing pirfenidone with placebo, was stopped early when a planned interim analysis indicated a statistically significant benefit of pirfenidone over placebo. ${ }^{39}$ PANTHER involved 3 arms: placebo, N-acetylcysteine alone, and triple therapy. ${ }^{37}$ A planned interim analysis indicated that patients in the triple therapy arm had an increased rate of death and hospitalization compared with patients in the placebo arm. The triple therapy arm was terminated due to these safety concerns, but the $\mathrm{N}$-acetylcysteine and placebo arms continued as planned.

There were differences between studies in terms of whether patients could receive rescue medication. The INPULSIS trials of nintedanib allowed for rescue treatment if there was disease progression after 6 months. ${ }^{38}$ This was not the case in the pirfenidone trials. ${ }^{26,34}$ There were also differences in corticosteroid use between studies (where reported, concomitant use of corticosteroids ranged from $0.3 \%$ in CAPACITY 1 to $49.1 \%$ in TOMORROW ${ }^{26,40}$ ). An analysis of the INPULSIS data found no evidence that corticosteroid use at baseline influenced the relative effectiveness of nintedanib (vs. placebo) for the rate of decline in FVC.42

A pragmatic approach was taken for the NMA in that all trials were included, regardless of differences in baseline characteristics, dosing, discontinuation rates, loss to follow-up, and how missing data were handled. Although some methods 
FIGURE 3 Results of the Principal Analyses: Forest Plots for Key Comparisons

\section{A. Change from Baseline in FVC/VC (L) ${ }^{\mathrm{a}}$}

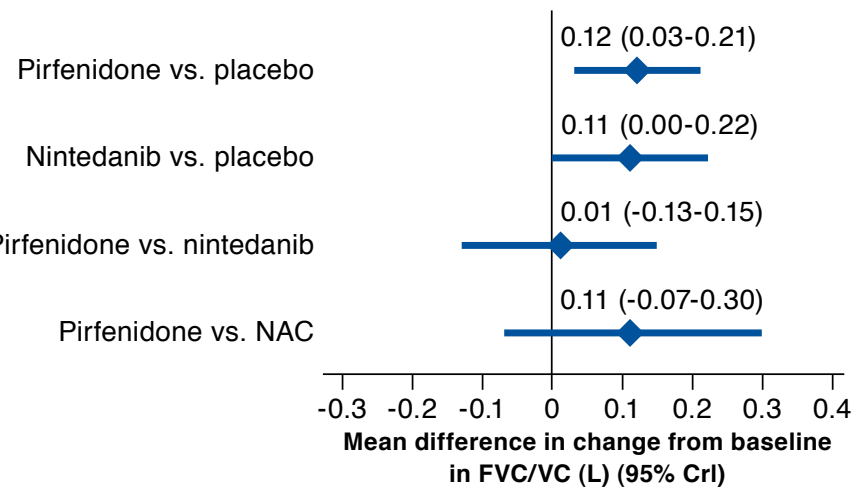

\section{C. $10 \%$ Reduction in FVC/VCc}

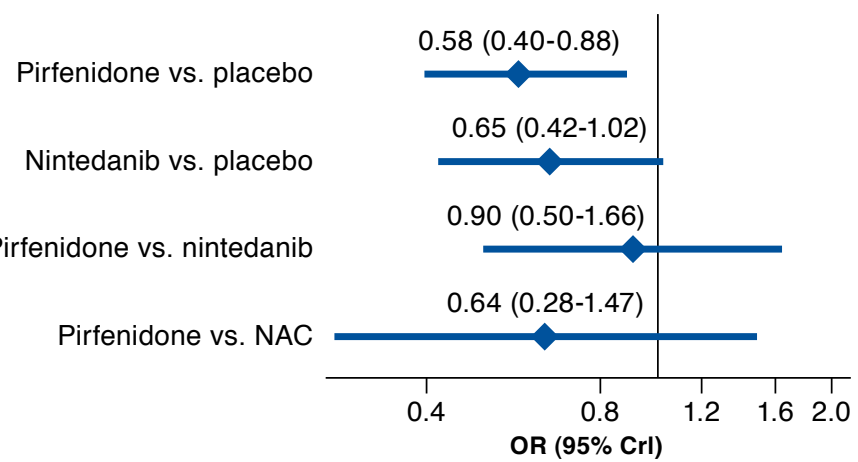

\section{B. Change from Baseline in Percent Predicted FVC/VC}

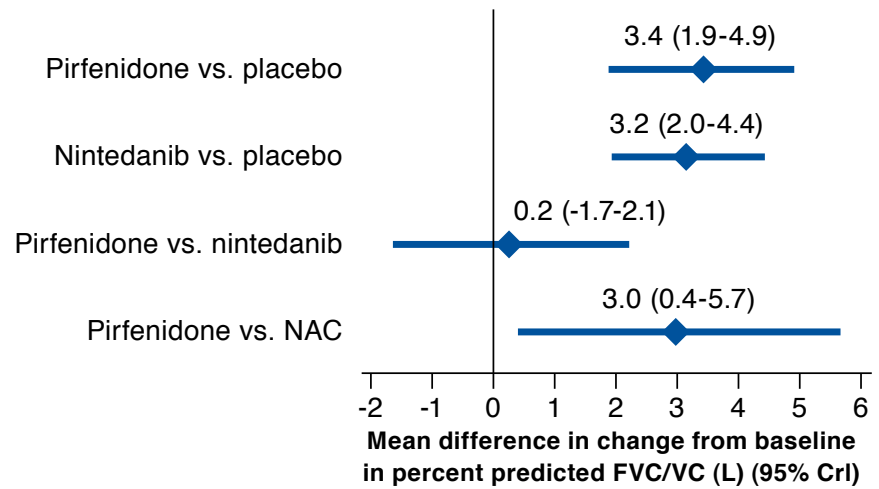

D. All-Cause Mortality at $\mathbf{5 2}$ Weeks $^{c}$

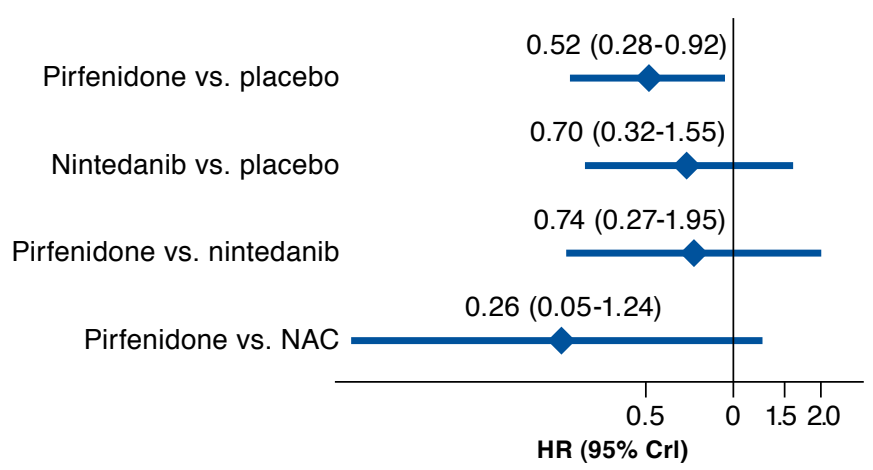

Note: For SP3, pirfenidone 1,800 mg/day is assumed to be equivalent to pirfenidone 2,403 $\mathrm{mg} /$ day.

${ }^{a}$ For each line of results, the mean difference is calculated as the treatment listed first minus the treatment/placebo listed second; a positive result is therefore favorable to the treatment listed first. For example, the top result shows the mean change from baseline for pirfenidone minus the mean change from baseline for placebo. The results indicate that patients who receive pirfenidone will decline, on average, by $0.12 \mathrm{~L}$ of FVC less than patients who receive placebo.

${ }^{b}$ For each line of results, the mean difference is calculated as the treatment listed first minus the treatment/placebo listed second; a positive result is therefore favorable to the treatment listed first. For example, the top result shows the mean change from baseline for pirfenidone minus the mean change from baseline for placebo. The results indicate that patients who receive pirfenidone will decline, on average, by $3.4 \mathrm{FVC}$ percentage points less than patients who receive placebo.

'For each line of results in each graph, an OR (in Fig. 3C) or an HR (Fig. 3D) is provided for the treatment listed first, relative to the treatment/placebo listed second; a result less than 1 is favorable to the treatment listed first.

$C r I=$ credible interval; $F V C=$ forced vital capacity; $H R=$ hazard ratio; $L=$ liter $; N A C=N$-acetylcysteine; $O R=o d d s$ ratio; $V C=$ vital capacity.

for handling missing data may produce biased results, imposing strict criteria on the handling of such data would have excluded most trials from the network.

Networks were developed for change in FVC ( $\mathrm{L}$ and percent predicted); categorical declines in percent predicted FVC; change in 6MWD; change in health-related quality of life; all-cause mortality; IPF-related mortality; PFS; acute exacerbations; all-cause discontinuation of study; and all-cause discontinuation of treatment. However, only change from baseline in FVC, decline in percent predicted FVC of $\geq 10 \%$, and all-cause mortality are explored in this article, because these are the most clinically relevant outcomes for which sound evidence was available for both pirfenidone and nintedanib. For nintedanib, at the time of analysis, no data were available for PFS and 6MWD. For acute exacerbations, data were available for both pirfenidone and nintedanib; however, the studies define the outcome differently, and hence the NMA lacks validity.

\section{Synthesis of Results}

For pirfenidone, nintedanib, and N-acetylcysteine, each of the trials that measured change in FVC in L at approximately 52 weeks observed a smaller reduction in FVC in the active treatment groups compared with placebo. ${ }^{26,33-40}$ For all-cause mortality, there were higher rates of mortality in the placebo 
Systematic Review and Network Meta-analysis of Idiopathic Pulmonary Fibrosis Treatments

TABLE 2 Summary of NMA Results (Base-Case and Sensitivity Analyses)

\begin{tabular}{|c|c|c|c|c|c|c|c|}
\hline \multirow[b]{2}{*}{ Outcome } & \multirow[b]{2}{*}{ Measure } & \multirow[b]{2}{*}{$\begin{array}{l}\text { Time } \\
\text { Point }\end{array}$} & \multirow[b]{2}{*}{ Criterion } & \multirow[b]{2}{*}{ Model Type } & \multicolumn{3}{|c|}{ Estimate $(95 \% \mathrm{CrI})$} \\
\hline & & & & & $\begin{array}{l}\text { Pirfenidone vs. } \\
\text { Placebo }\end{array}$ & $\begin{array}{l}\text { Nintedanib vs. } \\
\text { Placebo }\end{array}$ & $\begin{array}{l}\text { Pirfenidone vs. } \\
\text { Nintedanib }\end{array}$ \\
\hline \multirow[t]{5}{*}{$\overline{\mathrm{FVC}(\mathrm{L})}$} & \multirow{5}{*}{$\begin{array}{c}\text { Mean } \\
\text { difference } \\
\text { in change } \\
\text { from } \\
\text { baseline }\end{array}$} & \multirow{5}{*}{\begin{tabular}{|c|} 
Approx. \\
52 weeks
\end{tabular}} & Phase III & Random effects & $0.12(0.03$ to 0.21$)$ & $0.11(0.00$ to 0.22$)$ & $0.01(-0.13$ to 0.15$)$ \\
\hline & & & Sensitivity to choice of prior & Random effects & $0.11(0.03$ to 0.21$)$ & $0.11(0.00$ to 0.22$)$ & $0.00(-0.13$ to 0.16$)$ \\
\hline & & & Phase III & Fixed effect & $0.11(0.06$ to 0.15$)$ & $0.11(0.08$ to 0.14$)$ & $0.00(-0.06$ to 0.05$)$ \\
\hline & & & Expanded network (Ph II and Ph III) & Random effects & $0.12(0.04$ to 0.20$)$ & $0.12(0.04$ to 0.21$)$ & $0.00(-0.12$ to 0.11$)$ \\
\hline & & & Expanded network (Ph II and Ph III) & Fixed effect & $0.11(0.06$ to 0.15$)$ & $0.11(0.09$ to 0.14$)$ & $-0.01(-0.06$ to 0.05$)$ \\
\hline \multirow{5}{*}{$\begin{array}{l}\text { Percent } \\
\text { predicted } \\
\text { FVC }\end{array}$} & \multirow{5}{*}{$\begin{array}{c}\text { Mean } \\
\text { difference } \\
\text { in change } \\
\text { from } \\
\text { baseline }\end{array}$} & \multirow{5}{*}{$\begin{array}{l}\text { Approx. } \\
52 \text { weeks }\end{array}$} & Phase III & Random effects & $3.39(1.92$ to 4.86$)$ & 3.15 (1.96 to 4.35$)$ & $0.23(-1.66$ to 2.13$)$ \\
\hline & & & Sensitivity to choice of prior & Random effects & $3.40(1.37$ to 5.47$)$ & $3.15(0.72$ to 5.59$)$ & $0.24(-2.90$ to 3.44$)$ \\
\hline & & & Phase III & Fixed effect & $3.37(2.06$ to 4.69$)$ & $3.15(2.35$ to 3.96$)$ & $0.22(-1.33$ to 1.76$)$ \\
\hline & & & Expanded network (Ph II and Ph III) & Random effects & $3.39(1.94$ to 4.84$)$ & $3.33(2.34$ to 4.50$)$ & $0.05(-1.81$ to 1.80$)$ \\
\hline & & & Expanded network (Ph II and Ph III) & Fixed effect & $3.37(2.06$ to 4.69$)$ & $3.30(2.52$ to 4.07$)$ & $0.08(-1.45$ to 1.61$)$ \\
\hline \multirow{5}{*}{$\begin{array}{l}\text { Decline } \\
\text { in percent } \\
\text { predicted } \\
\text { FVC of } \\
\geq 10 \%\end{array}$} & \multirow[t]{5}{*}{ OR } & \multirow{5}{*}{$\begin{array}{l}\text { Approx. } \\
52 \text { weeks }\end{array}$} & Phase III & Random effects & $0.58(0.40$ to 0.88$)$ & $0.65(0.42$ to 1.02$)$ & $0.90(0.50$ to 1.66$)$ \\
\hline & & & Sensitivity to choice of prior & Random effects & $0.59(0.36$ to 0.98$)$ & $0.65(0.37$ to 1.16$)$ & $0.90(0.42$ to 1.95$)$ \\
\hline & & & Phase III & Fixed effect & $0.58(0.44$ to 0.75$)$ & $0.65(0.51$ to 0.85$)$ & $0.88(0.61$ to 1.27$)$ \\
\hline & & & Expanded network (Ph II and Ph III) & Random effects & $\mathrm{NA}$ & $\mathrm{NA}$ & $\mathrm{NA}$ \\
\hline & & & Expanded network (Ph II and Ph III) & Fixed effect & $\mathrm{NA}$ & $\mathrm{NA}$ & $\mathrm{NA}$ \\
\hline \multirow{15}{*}{$\begin{array}{l}\text { All-cause } \\
\text { mortality }\end{array}$} & \multirow[t]{5}{*}{ HR } & \multirow{5}{*}{$\begin{array}{c}\text { Approx. } \\
52 \text { weeks }\end{array}$} & Phase III & Random effects & $0.52(0.28$ to 0.92$)$ & $0.70(0.32$ to 1.55$)$ & $0.74(0.27$ to 1.95$)$ \\
\hline & & & Sensitivity to choice of prior & Random effects & $0.51(0.25$ to 1.02$)$ & $0.70(0.23$ to 2.13$)$ & $0.73(0.19$ to 2.67$)$ \\
\hline & & & Phase III & Fixed effect & $0.52(0.32$ to 0.84$)$ & $0.70(0.43$ to 1.13$)$ & $0.74(0.37$ to 1.46$)$ \\
\hline & & & Expanded network (Ph II and Ph III) & Random effects & $0.48(0.27$ to 0.82$)$ & $0.72(0.40$ to 1.28$)$ & $0.67(0.29$ to 1.45$)$ \\
\hline & & & Expanded network (Ph II and Ph III) & Fixed effect & $0.49(0.30$ to 0.79$)$ & $0.71(0.46$ to 1.10$)$ & $0.68(0.36$ to 1.30$)$ \\
\hline & \multirow[t]{5}{*}{ HR } & \multirow{5}{*}{$\begin{array}{c}\text { Approx. } \\
72 \text { weeks }\end{array}$} & Phase III & Random effects & $0.61(0.36$ to 1.04$)$ & $0.70(0.32$ to 1.53$)$ & $0.88(0.34$ to 2.23$)$ \\
\hline & & & Sensitivity to choice of prior & Random effects & $0.61(0.31$ to 1.15$)$ & $0.70(0.24$ to 2.08$)$ & $0.88(0.24$ to 3.02$)$ \\
\hline & & & Phase III & Fixed effect & $0.62(0.40$ to 0.95$)$ & $0.70(0.43$ to 1.13$)$ & $0.88(0.47$ to 1.68$)$ \\
\hline & & & Expanded network (Ph II and Ph III) & Random effects & $0.58(0.34$ to 0.93$)$ & $0.72(0.40$ to 1.29$)$ & $0.81(0.36$ to 1.68$)$ \\
\hline & & & Expanded network (Ph II and Ph III) & Fixed effect & $0.59(0.39$ to 0.89$)$ & $0.71(0.46$ to 1.10$)$ & $0.82(0.45$ to 1.50$)$ \\
\hline & \multirow[t]{5}{*}{ OR } & \multirow{5}{*}{$\begin{array}{c}\text { Approx. } \\
52 \text { weeks }\end{array}$} & Phase III & Random effects & $0.50(0.29$ to 0.84$)$ & $0.69(0.37$ to 1.26$)$ & $0.72(0.32$ to 1.62$)$ \\
\hline & & & Sensitivity to choice of prior & Random effects & $0.50(0.28$ to 0.85$)$ & $0.69(0.36$ to 1.32$)$ & $0.72(0.31$ to 1.69$)$ \\
\hline & & & Phase II & Fixed effect & $0.50(0.30$ to 0.81$)$ & $0.69(0.42$ to 1.12$)$ & $0.73(0.36$ to 1.46$)$ \\
\hline & & & Expanded network (Ph II and Ph III) & Random effects & $0.50(0.29$ to 0.84$)$ & $0.70(0.42$ to 1.19$)$ & $0.71(0.33$ to 1.48$)$ \\
\hline & & & Expanded network (Ph II and Ph III) & Fixed effect & $0.50(0.30$ to 0.81$)$ & $0.70(0.45$ to 1.10$)$ & $0.71(0.36$ to 1.39$)$ \\
\hline
\end{tabular}

arms compared with pirfenidone and nintedanib. ${ }^{26,33,34,38-40}$ However, in trials of N-acetylcysteine and triple therapy, mortality was higher in the active treatment arms compared with placebo $^{35-37}$ (results of the individual trials are presented in Appendix E).

The results of the assessments of heterogeneity and the principal NMAs are summarized below. It was not necessary to conduct an assessment of inconsistency because none of the networks included any comparisons that were informed by both direct and indirect evidence. Further details on all results are included in Table 2 and Appendix F.

The base-case networks for the change from baseline in FVC include pirfenidone, nintedanib, $\mathrm{N}$-acetylcysteine, and placebo. For these outcomes, the pairwise comparisons of pirfenidone and placebo exhibited low to moderate heterogeneity (I-squared statistic: $50 \%$ for FVC in L and $24.4 \%$ for percent predicted FVC). The pairwise comparisons of nintedanib and placebo exhibited minimal heterogeneity (I-squared statistic: 0\%).

The NMAs indicate that, relative to placebo, both pirfenidone and nintedanib slow the decline in FVC over 1 year. There is no evidence that $\mathrm{N}$-acetylcysteine is more effective than placebo. There is also no evidence of a difference between pirfenidone and nintedanib. These conclusions are supported by all of the sensitivity analyses.

The principal NMA found that for change from baseline in FVC over 52 weeks, patients receiving pirfenidone declined by an average of $0.12 \mathrm{~L}$ less than patients receiving placebo (95\% CrI $=0.03-0.21 \mathrm{~L}$ ), and patients receiving nintedanib declined by $0.11 \mathrm{~L}$ less than patients receiving placebo (95\% CrI =0.00-0.22 L; although the CrI for nintedanib 
includes zero at 2 decimal places in the base case, the sensitivity analyses suggest that there is a difference in effect between nintedanib and placebo for this endpoint; Figure 3A). Patients receiving $\mathrm{N}$-acetylcysteine declined by an average of $0.01 \mathrm{~L}$ less than patients receiving placebo $(95 \% \mathrm{CrI}=-0.15-0.17 \mathrm{~L}$; Table F2 in Appendix F). For percent predicted FVC over 52 weeks, patients receiving pirfenidone declined by an average of 3.4 percentage points less than patients receiving placebo (95\% CrI $=1.9 \%-4.9 \%$ ), and patients receiving nintedanib declined by 3.2 percentage points less than patients receiving placebo (95\% CrI $=2.0 \%-4.4 \%$; Figure 3B).

The base-case network for the decline in percent predicted FVC of $\geq 10 \%$ included pirfenidone, nintedanib, $\mathrm{N}$-acetylcysteine, and placebo. The pairwise comparisons of pirfenidone versus placebo and nintedanib versus placebo both exhibited moderate heterogeneity, with I-squared statistics of $40.8 \%$ and $40.0 \%$, respectively.

The principal NMA found that, relative to placebo, patients treated with pirfenidone have lower odds of experiencing a decline in percent predicted FVC of $\geq 10 \%$ over 1 year (OR: $0.58,95 \% \mathrm{CrI}=0.40-0.88$; Figure 3C). There is no conclusive evidence of a difference between nintedanib and placebo (OR: 0.65, 95\% CrI=0.42-1.02; Figure 3C). There is no evidence that $\mathrm{N}$-acetylcysteine is more effective than placebo, and there is no evidence of a difference between any of the active treatments. These conclusions are supported by all of the sensitivity analyses, with the exception that the FE model indicated that both pirfenidone and nintedanib are superior to placebo.

The base-case network for all-cause mortality included pirfenidone, nintedanib, $\mathrm{N}$-acetylcysteine, and placebo. The pairwise comparison for pirfenidone versus placebo exhibited minimal heterogeneity (I-squared statistic: 0\%). The comparison of nintedanib versus placebo was only informed by a pooled result from the INPULSIS trials.

The principal analysis indicated that, compared with placebo, pirfenidone reduced all-cause mortality over 1 year (HR: 0.52, 95\% CrI=0.28-0.92; Figure 3D). This conclusion is supported by most of the sensitivity analyses: 11 of the 14 sensitivity analyses found evidence of a difference between pirfenidone and placebo (Table 2). None of the analyses suggest that nintedanib is more effective than placebo, or that $\mathrm{N}$-acetylcysteine is more effective than placebo. Furthermore, most of the analyses do not provide evidence of a difference between pirfenidone, nintedanib, and $\mathrm{N}$-acetylcysteine. One sensitivity analysis suggests that pirfenidone is superior to $\mathrm{N}$-acetylcysteine. Based on the principal analysis, the HR for nintedanib versus placebo is 0.70 ( $95 \% \mathrm{CrI}=0.32-1.55)$, the $\mathrm{HR}$ for $\mathrm{N}$-acetylcysteine versus placebo is 2.00 (95\% CrI $=0.46-$ 8.62), and the HR for pirfenidone versus nintedanib is 0.74 (95\% CrI =0.27-1.95; Figure 3D).

\section{Discussion}

This SR identified 9 trials that were eligible for inclusion in the NMA. Our analyses found that treatment with either pirfenidone or nintedanib reduced the decline in lung function over a year by approximately 0.1 L relative to placebo, which should be considered a clinically meaningful reduction. ${ }^{43}$ The results suggest that pirfenidone also reduces the rate of all-cause mortality over a year, with an HR of 0.52 relative to placebo. For nintedanib, no significant effect was observed; however, it should be noted that the relevant studies conducted to date have not been powered to identify any difference in mortality rates.

Our SR and NMA follow several other MAs and NMAs of treatments for IPF. MAs and NMAs for IPF have recently been published by Loveman et al. (2015), ${ }^{19}$ Canestaro et al. (2016), ${ }^{14}$ Rochwerg et al. (2016), ${ }^{21}$ and Rogliani et al. (2016). ${ }^{23}$ The recently updated American Thoracic Society (ATS)/European Respiratory Society (ERS) IPF treatment guidelines (2015) report MAs of IPF treatments with placebo. Furthermore, additional MAs and NMAs have been conducted to inform assessments by the SMC, ${ }^{10,11}$ EMA, ${ }^{15,16}$ Swissmedic, ${ }^{24,25}$ the FDA, ${ }^{17,18}$ and other authorities, including a recent NMA that was conducted as part of an STA of nintedanib for the treatment of IPF. ${ }^{20}$

A key advantage of our analysis is that it includes additional data on pirfenidone, which have not previously been made publicly available. An important assumption of NMA is that the studies should be similar in terms of any characteristics that may impact the treatment effect. Additional 1-year results from the CAPACITY studies have allowed us to ensure that the NMAs included similar time points from all studies. Additional FVC results from the CAPACITY studies and ASCEND have allowed us to conduct a thorough assessment of the effect of the treatments on change from baseline in FVC.

In most cases, the additional data have not affected the results, and our NMA reached the same conclusions as the analyses identified above. For mortality, all the NMAs concluded that there was no evidence of a difference between pirfenidone and nintedanib. ${ }^{14,19-21}$ However, some differences in the effect on mortality were observed for the comparisons between nintedanib and placebo, and between pirfenidone and placebo. Our NMA and all but 1 of the other analyses do not report a difference between nintedanib and placebo. ${ }^{5,11,14-16,18-21,24,25}$ The only exception is Rogliani et al., ${ }^{23}$ who find that nintedanib is superior to placebo.

As per our principal analysis (and most of our sensitivity analyses), the Loveman et al. NMA, ${ }^{19}$ the SMC, ${ }^{10,11}$ the EMA, $, 15,16$ and Swissmedic ${ }^{24,25}$ all concluded that pirfenidone improved all-cause mortality compared with placebo. In our NMA, the comparison of pirfenidone with placebo led to an HR of 0.52 (95\% CrI $=0.28-0.92$ ) (based on data up to 52 weeks) and an OR of $0.50(95 \% \mathrm{CrI}=0.29-0.84)$. 
In contrast to our analysis, the $\mathrm{FDA},{ }^{17}$ the ATS/ERS IPF treatment guidelines, ${ }^{5}$ the Canestaro et al. NMA,${ }^{14}$ the Rochwerg et al. NMA, ${ }^{21}$ the Rogliani et al. MA, ${ }^{23}$ and the STA submission for nintedanib ${ }^{20}$ found that pirfenidone had no significant effect on mortality. These analyses differ from our own principal analysis in various ways: All include different time points, some use ORs, relative risks, or risk differences rather than HRs, and some use FE models rather than RE models. We believe that the primary reason that these analyses have reached different conclusions from our own is that they combine data from different time points. Our principal NMA was based on HRs and used results up to approximately 52 weeks. Therefore, our approach did not require the additional assumption of proportional hazards to compare data collected at different time points. In particular, the FDA evaluation of pirfenidone for all-cause mortality used data collected at the end of each study (ASCEND $=52$ weeks; CAPACITY $=72$ weeks [and up to 120 weeks for the patients who were recruited earliest]), resulting in a nonsignificant HR of 0.75 (95\% confidence interval $=0.51-1.11$ ) versus placebo. ${ }^{17}$

For our OR NMA, we only included results from 52 to 60 weeks; we used 52-week data from the CAPACITY studies and excluded SP2 because it only had data available up to 36 weeks. Likewise, the Loveman et al. NMA, which was based on ORs, also excluded SP2 and incorporated 52-week data from the CAPACITY studies that were presented at the ATS International Conference in $2014 .{ }^{44}$ However, the other NMAs that evaluated mortality on the OR scale (the Canestaro et al. NMA, the Rochwerg et al. NMA, and the NMA conducted as part of the STA for nintedanib) incorporated data from more diverse time points.

For the CAPACITY studies, these 3 NMAs incorporated the overall all-cause mortality results presented in Noble et al. (2011). ${ }^{26}$ This result is based on a treatment duration of 72 weeks and includes all deaths that were reported during the study period, with a follow-up of 120 weeks for the patients who were recruited earliest. Similarly, the results in Rogliani et al. are consistent with on-treatment, all-cause mortality, as reported in Noble et al. ${ }^{23,26}$ This estimate includes deaths that occurred in the period from randomization until 28 days after the last dose of study drug (potentially up to 76 weeks). The ATS/ERS IPF treatment guidelines ${ }^{5}$ summarized mortality on the relative risks scale, and although they do not explicitly identify the data that they used, it is assumed that they also used the results presented in Noble et al. ${ }^{26}$

Our OR NMA makes the assumption that treatment effects will be similar across time points ranging from 52 to 60 weeks, whereas the other analyses make the bolder assumption that treatment effects will be similar across a wider time frame. It is unknown whether treatment effects observed at 52 weeks will be the same over the longer term. Consequently, incorporating the bolder assumption may bias the analysis; this was observed by the NICE Evidence Review Group. ${ }^{27}$
Change from baseline in FVC was evaluated by the Loveman et al. NMA,${ }^{19}$ the Canestaro et al. NMA,${ }^{14}$ the ATS/ERS guidelines, ${ }^{5}$ and the Rogliani et al. MA. ${ }^{23}$ However, for this outcome, the Canestaro et al. NMA neither included pirfenidone nor reported the result for nintedanib versus placebo. The Loveman et al. NMA, the ATS/ERS guidelines, the Rogliani et al. MA, and our NMA all concluded that both pirfenidone and nintedanib are more effective than placebo. Our NMA found no evidence of a difference between nintedanib and pirfenidone.

However, Loveman et al. ${ }^{19}$ and Rogliani et al. ${ }^{23}$ both concluded that nintedanib is superior to pirfenidone for change from baseline in FVC. The most likely cause of these divergent findings is that both of these analyses relied on a standardized mean difference (SMD) approach ${ }^{45}$ to combine percent predicted FVC and FVC (L), because neither of these measurements were publicly available from all of the pirfenidone studies. In our NMA, an SMD approach was unnecessary because we had access to both types of FVC measures for all of the Phase III pirfenidone studies. Our principal and sensitivity analyses of FVC found no evidence of a difference between pirfenidone and nintedanib.

We conducted a detailed review of the data and methodology to explore why our NMA and the Loveman et al. NMA ${ }^{19}$ reached different conclusions for change from baseline in FVC. We found that the difference could be largely attributed to the use of the SMD approach. The same conclusions apply to the Rogliani work. ${ }^{23}$ Furthermore, Loveman et al. ${ }^{19}$ used an FE model for their principal analysis, whereas in our analysis we considered an RE model more appropriate than an FE model because of the variability between studies characteristics (Appendix D). As a sensitivity analysis, Loveman et al. also conducted an RE model, which found no evidence of difference between pirfenidone and nintedanib.

With respect to Loveman et al.'s use of the SMD approach, ${ }^{19}$ for both FVC (L) and percent predicted FVC, the pirfenidone and nintedanib studies reported similar mean differences with respect to placebo. However, some of the pirfenidone studies reported larger standard deviations (Figures Fl to F6 in Appendix F). Hence, although the mean differences are similar, the SMDs (which are calculated by dividing the mean difference by the pooled standard deviation) favor nintedanib and lead to a conclusion, in both Loveman et al. and Rogliani et al., that is in conflict with the analysis based on the raw mean differences.

Although the SMD approach is a useful tool for combining different measurements in an MA or NMA, it requires the assumption that any variability in the standard deviations reflects differences in the measurement scale rather than differences in the patient population. ${ }^{46}$ Ades et al. (2015) identified that it is common for patient-to-patient variability to differ between trials and questioned the appropriateness of the SMD approach. ${ }^{47}$ In addition, for NMAs, we suggest that it is 
important to review the standard deviations by treatment, in order to determine whether the SMD approach may favor 1 treatment over another. For change from baseline in percent predicted FVC, the standard deviations are much higher for the pirfenidone studies than for the nintedanib studies. ${ }^{19}$ Our view is that the SMD approach is not appropriate for this dataset and hence that the conclusion reached by Loveman et al. and Rogliani et al., that nintedanib is more effective than pirfenidone in terms of change from baseline in FVC, is inappropriate. ${ }^{19,23}$

Rogliani et al. is the only NMA to date in the public domain to have found that nintedanib is superior to pirfenidone on change from baseline in FVC and, even more surprisingly, superior to placebo on mortality, finding no evidence of a difference between pirfenidone and placebo on mortality. ${ }^{23}$ In addition to combining data from diverse time points, as described above, and analyzing mortality on the risk difference scale, the most likely causes of these differences between Rogliani et al.'s MAs and this NMA is how the pirfenidone and nintedanib doses have been handled.

In their base-case analysis, Rogliani et al. assume that all of the available pirfenidone doses $(1,197,1,200,1,800$, and $2,403 \mathrm{mg}$ /day) are equally safe and effective. ${ }^{23}$ Likewise, for nintedanib, they have assumed that the 50, 100, 200, and $300 \mathrm{mg} /$ day doses are equally safe and effective. ${ }^{23}$ However, when these doses were compared in the TOMORROW study, only the $300 \mathrm{mg} /$ day dose was significantly more effective than placebo in reducing the annual rate of change in FVC (L), with no evidence of an effect for the other doses. ${ }^{40}$ Where studies included multiple doses of a drug, Rogliani et al. have entered each dose into the MA as if it were a separate study. ${ }^{23}$ This method is inappropriate and could potentially lead to false conclusions.

\section{Limitations}

Flaws in the design, conduct, and analysis of RCTs can lead to bias and can raise questions about the validity of their findings. In this review, a similarity assessment of studies eligible for inclusion in the networks was undertaken, as well as a full assessment of the risk of bias for each trial identified for inclusion in the base-case network. The triple therapy arm of the PANTHER trial was terminated early after a mean follow-up of 32 weeks compared with the planned duration of 60 weeks. ${ }^{37}$ This treatment arm was excluded from the primary analysis because of this fact but did feature in a sensitivity analysis.

Pirfenidone and nintedanib are the most promising treatments currently available for IPF. However, a head-to-head RCT of these treatments has yet to be conducted. In the absence of direct evidence, we have used indirect comparisons to evaluate the relative efficacy of the treatments. Although indirect comparison methods are now well established and have been heralded as "the next-generation evidence synthesis tool," ${ }^{\prime 48}$ they do require several assumptions, primarily that all of the studies in the network are sufficiently similar in terms of their patient populations, treatments administered, and outcomes measured.

We have endeavored to ensure that the outcomes measured are as similar as possible across the studies by sourcing previously unpublished pirfenidone data at 52 weeks. However, there were some differences between the studies that could not be avoided. The INPULSIS trials allowed for rescue treatment if there was disease progression after 6 months and permitted the use of corticosteroids ( $\leq 15 \mathrm{mg}$ /day prednisone or equivalent). ${ }^{38}$ Corticosteroids were not permitted in the pirfenidone trials (except for short-term treatment of acute exacerbations of IPF). ${ }^{26,34}$ However, we do not consider these differences to be clinically important, as corticosteroids have not been shown to have a benefit in IPF in controlled trials, and an analysis of the INPULSIS data found no evidence that corticosteroid use at baseline influenced the effectiveness of nintedanib in reducing the rate of FVC decline.,42 The studies also differed in the statistical methods used to handle missing data, and these differences may have affected the results.

The RCTs included in our NMA only admitted adult patients with suspected or diagnosed mild to moderate IPF. Our results cannot be generalized to other types of patients; e.g., those who were excluded from the RCTs for having advanced disease or a high chance of requiring a lung transplant. The maximum treatment duration was 52 weeks for nintedanib and up to 120 weeks for pirfenidone. Most of our analyses predict the efficacy of pirfenidone and nintedanib at 52 weeks (a sensitivity analysis of all-cause mortality provides predictions up to 72 weeks). Further research is therefore required to evaluate the long-term efficacy of these treatments.

Only studies published in English were included in our SR and NMA. However, we do not believe that this restriction excluded any additional data, as the Loveman et al. NMA, which did not have this restriction, included the same studies. ${ }^{19}$

\section{Conclusions}

This systematic review identified 9 trials that could contribute to an NMA of treatments for IPF. Our primary analysis indicates that pirfenidone and nintedanib are effective treatments for IPF, with both treatments reducing the decline in lung function over a year compared with placebo. N-acetylcysteine was found to be no more effective than placebo. The results of this analysis also suggest that, during the first year of treatment, pirfenidone reduces the odds of experiencing a decline in percent predicted FVC of $\geq 10 \%$ compared with placebo, and reduces the rate of all-cause mortality, with an HR of 0.52 relative to placebo. 


\section{Authors}

KELLY FLEETWOOD, MSc, Quantics Consulting, Edinburgh, United Kingdom. RACHAEL MCCOOL, BSc, and JULIE GLANVILLE, MSc, York Health Economics Consortium, York, United Kingdom. SUSAN C. EDWARDS, PhD; SANDRO GSTEIGER, PhD; and MONICA DAIGL, MSc, MORSE Health Technology Assessment Group, Global Pricing and Market Access, F. Hoffmann-La Roche, Pharmaceuticals Division, Basel, Switzerland. MARK FISHER, MSc, FIECON, St Albans, United Kingdom.

AUTHOR CORRESPONDENCE: Kelly Fleetwood, MSc, Quantics Consulting, 28 Drumsheugh Gardens, Edinburgh, EH3 7RN, United Kingdom. Tel.: +44 (0) 131 4402781, x200;

E-mail: Kelly.Fleetwood@quantics.co.uk

\section{DISCLOSURES}

Fleetwood is an employee of Quantics Consulting. McCool and Glanville are employees of York Health Economics Consortium (YHEC). Quantics and YHEC received funding from F. Hoffmann-La Roche for conducting the systematic review and network meta-analysis reported in this paper. Edwards, Gsteiger, and Daigl are employees of F. Hoffmann-La Roche. Fisher was employed by InterMune UK, a wholly owned Roche subsidiary, until July 2015. He is currently employed by FIECON, which has received funding from F. Hoffmann-La Roche for consulting services.

The systematic review and network meta-analysis reported in this paper were conducted by Fleetwood (Quantics Consulting) and McCool and Glanville (YHEC), funded by F. Hoffmann-La Roche. The original network analysis was funded by InterMune.

Study concept and design were contributed by Edwards, Gsteiger, and Daigl, along with Fleetwood, McCool, and Glanville. Fleetwood, McCool, and Glanville collected the data, with assistance from Edwards, Gsteiger, and Daigl. Data interpretation was performed by Fleetwood and Fisher, with assistance from the other authors. The manuscript was written by Fleetwood, McCool, and Glanville, with assistance from Edwards, Daigl, and Fisher, and revised by all the authors.

\section{ACKNOWLEDGMENTS}

Medical writing support was provided by Katharine Howe on behalf of Complete Medical Communications, funded by F. Hoffmann-La Roche.

The authors acknowledge Nick Freemantle, for his work on data interpretation and manuscript revision; Mick Arber, an employee of YHEC, for his work on conducting the literature searches; Maria Cikalo, an employee of YHEC, for her assistance with data extraction and checking; and Mary Edwards, an employee of YHEC, who was a research assistant on this project.

\section{REFERENCES}

1. European Medicines Agency. Public summary of opinion on orphan designation: pirfenidone for the treatment of idiopathic pulmonary fibrosis. March 12, 2015. Available at: http://www.ema.europa.eu/docs/en_GB/document_library/Orphan_designation/2009/10/WC500006133.pdf. Accessed February 9, 2017.

2. Meltzer EB, Noble PW. Idiopathic pulmonary fibrosis. Orphanet J Rare Dis. 2008;3:8

3. du Bois RM. Idiopathic pulmonary fibrosis: present understanding and future options. Eur Respir Rev. 2011;20(121):132-33.

4. Raghu G, Collard HR, Egan JJ, et al. An official ATS/ERS/JRS/ALAT statement: idiopathic pulmonary fibrosis: evidence-based guidelines for diagnosis and management. Am J Respir Crit Care Med. 2011;183(6):788-824.
5. Raghu G, Rochwerg B, Zhang Y, et al. An official ATS/ERS/JRS/ALAT Clinical Practice Guideline: Treatment of Idiopathic Pulmonary Fibrosis: an update of the 2011 Clinical Practice Guideline. Am J Respir Crit Care Med. 2015;192(2):e3-19.

6. European Medicines Agency. EU/3/13/1123: Public summary of opinion on orphan designation: nintedanib for the treatment of idiopathic pulmonary fibrosis. March 3, 2015. Available at: http://www.ema.europa.eu/docs/ en_GB/document_library/Orphan_designation/2013/05/WC500143247.pdf. Accessed February 9, 2017

7. U.S. Food and Drug Administration. News release. FDA approves Esbriet to treat idiopathic pulmonary fibrosis. October 15, 2014. Available at: http:// www.fda.gov/NewsEvents/Newsroom/PressAnnouncements/ucm418991. htm. Accessed February 9, 2017.

8. U.S. Food and Drug Administration. News release. FDA approves Ofev to treat idiopathic pulmonary fibrosis. October 15, 2014. Available at: http:// www.fda.gov/NewsEvents/Newsroom/PressAnnouncements/ucm418994. htm. Accessed February 9, 2017.

9. National Clinical Guideline Centre (UK). Diagnosis and management of suspected idiopathic pulmonary fibrosis: idiopathic pulmonary fibrosis. 2013. National Institute for Health and Care Excellence: Clinical Guidelines, No. 163. Available at: https://www.ncbi.nlm.nih.gov/pubmedhealth/ PMH0068972/. Accessed February 9, 2017.

10. Scottish Medicines Consortium. Pirfenidone (Esbriet). August 12, 2013 Available at: https://www.scottishmedicines.org.uk/SMC_Advice/Advice/835_ 13_pirfenidone_Esbriet. Accessed February 9, 2017.

11. Scottish Medicines Consortium. Nintedanib (Ofev). October 12, 2015. Available at: https://www.scottishmedicines.org.uk/SMC_Advice/Advice/1076_ 15_nintedanib_Ofev. Accessed February 9, 2017.

12. Behr J, Kreuter M, Hoeper MM, et al. Management of patients with idiopathic pulmonary fibrosis in clinical practice: the INSIGHTS-IPF registry. Eur Respir J. 2015;46(1):186-96.

13. Bradley B, Branley HM, Egan JJ, et al. Interstitial lung disease guideline: the British Thoracic Society in collaboration with the Thoracic Society of Australia and New Zealand and the Irish Thoracic Society. Thorax. 2008;63(Suppl 5):vl-58.

14. Canestaro WJ, Forrester SH, Raghu G, Ho L, Devine BE. Drug treatment of idiopathic pulmonary fibrosis: systematic review and network meta-analysis. Chest. 2016;149(3):756-66.

15. European Medicines Agency. European public assessment report for Esbriet pirfenidone. August 31, 2016. Available at: http://www.ema.europa. eu/ema/index.jsp?curl=pages/medicines/human/medicines/002154/human_ med_001417.jsp\&mid=WC0b0lac058001d124. Accessed February 9, 2017.

16. European Medicines Agency. European public assessment report for Ofev nintedanib. October 20, 2016. Available at: http://www.ema.europa. eu/ema/index.jsp?curl=pages/medicines/human/medicines/003821/human_ med_001834.jsp\&mid=WCOb0lac058001d124. Accessed February 9, 2017.

17. U.S. Food and Drug Administration. Summary review of regulatory action-Esbriet. October 10, 2014. Available at: http://www.accessdata. fda.gov/drugsatfda_docs/nda/2014/022535Origls000SumR.pdf. Accessed February 9, 2017.

18. U.S. Food and Drug Administration. Summary review of regulatory action-Ofev. October 10, 2014. Available at: http://www.accessdata.fda.gov/ drugsatfda_docs/nda/2014/205832Origls000SumR.pdf. Accessed February 9, 2017.

19. Loveman E, Copley VR, Scott DA, Colquitt JL, Clegg AJ, O'Reilly KM. Comparing new treatments for idiopathic pulmonary fibrosis—a network meta-analysis. BMC Pulm Med. 2015;15:37.

20. National Institute for Health and Care Excellence. Idiopathic pulmonary fibrosis - nintedanib [ID752]: committee papers - 02 - Submission from the company - Boehringer Ingelheim. September 9, 2015. Available at: https:// www.nice.org.uk/guidance/TA379/documents/idiopathic-pulmonary-fibrosis-nintedanib-id752-committee-papers. Accessed February 9, 2017. 
21. Rochwerg B, Neupane B, Zhang Y, et al. Treatment of idiopathic pulmonary fibrosis: a network meta-analysis. BMC Med. 2016;14(1):18.

22. Rogliani P, Mura M, Mattia P, et al. HRCT and histopathological evaluation of fibrosis and tissue destruction in IPF associated with pulmonary emphysema. Respir Med. 2008;102(12):1753-61.

23. Rogliani P, Calzetta L, Cavalli F, Matera MG, Cazzola M. Pirfenidone, nintedanib and $\mathrm{N}$-acetylcysteine for the treatment of idiopathic pulmonary fibrosis: a systematic review and meta-analysis. Pulm Pharmacol Ther. 2016;40(1):95-103.

24. Swissmedic. Marketing authorisation - Esbriet, gélules (pirfenidonum). September 17, 2015. Available at: https://www.swissmedic.ch/zulassungen/00153/00189/00200/02983/index.html?lang=fr. Accessed February 9, 2017.

25. Swissmedic. Marketing authorisation - Ofev, capsules molles (nintedanibum). August 13, 2015. Available at: https://www.swissmedic.ch/zulassungen/00153/00189/00200/02936/index.html?lang=fr. Accessed February 9, 2017.

26. Noble PW, Albera C, Bradford WZ, et al. Pirfenidone in patients with idiopathic pulmonary fibrosis (CAPACITY): two randomised trials. Lancet. 2011;377(9779):1760-69.

27. National Institute for Health and Care Excellence. Idiopathic pulmonary fibrosis - nintedanib [ID752]: committee papers - 15 - Evidence Review Group report prepared by Southampton Health Technology Assessment Centre (SHTAC). September 11, 2015. Available at: https://www.nice.org. uk/guidance/TA379/documents/idiopathic-pulmonary-fibrosis-nintedanibid752-committee-papers. Accessed February 9, 2017.

28. Cottin V, Maher T, Azuma A, et al. Pirfenidone post-authorization safety registry (PASSPORT) update. Eur Respir J. 2015;46(Suppl 59):OA4500.

29. Miller MR, Hankinson J, Brusasco V, et al. Standardisation of spirometry. Eur Respir J. 2005;26(2):319-38.

30. Australian Pharmaceutical Benefits Advisory Committee (PBAC). Report of the Indirect Comparisons Working Group to the Pharmaceutical Benefits Advisory Committee: assessing indirect comparisons. 2009. Available at: http://www.pbs.gov.au/industry/useful-resources/pbac-technical-workinggroups-archive/indirect-comparisons-working-group-report-2008.pdf. Accessed March 1, 2017.

31. National Institute for Health and Care Excellence. Single technology appraisal (STA). Specification for manufacturer/sponsor submission of evidence. 2015. Available at: https://www.nice.org.uk/Media/Default/About/whatwe-do/NICE-guidance/NICE-technology-appraisals/specification-for-company-submission-of-evidence-2015-version.docx. Accessed February 9, 2017.

32. Higgins JP, Thompson SG, Deeks JJ, Altman DG. Measuring inconsistency in meta-analyses. BMJ. 2003;327(7414):557-60.

33. Taniguchi H, Ebina M, Kondoh Y, et al. Pirfenidone in idiopathic pulmonary fibrosis. Eur Respir J. 2010;35(4):821-29.

34. King TE Jr, Bradford WZ, Castro-Bernardini S, et al. A phase 3 trial of pirfenidone in patients with idiopathic pulmonary fibrosis. $N$ Engl J Med. 2014;370(22):2083-92.
35. Demedts M, Behr J, Buhl R, et al. High-dose acetylcysteine in idiopathic pulmonary fibrosis. N Engl J Med. 2005;353(21):2229-42.

36. Martinez FJ, de Andrade JA, Anstrom KJ, King TE Jr, Raghu G.

Randomized trial of acetylcysteine in idiopathic pulmonary fibrosis. N Engl J Med. 2014;370(22):2093-101.

37. Raghu G, Anstrom KJ, King TE Jr, Lasky JA, Martinez FJ. Prednisone, azathioprine, and $\mathrm{N}$-acetylcysteine for pulmonary fibrosis. N Engl J Med. 2012;366(21):1968-77.

38. Richeldi L, du Bois RM, Raghu G, et al. Efficacy and safety of nintedanib in idiopathic pulmonary fibrosis. N Engl J Med. 2014;370(22):2071-82.

39. Azuma A, Nukiwa T, Tsuboi E, et al. Double-blind, placebo-controlled trial of pirfenidone in patients with idiopathic pulmonary fibrosis. Am J Respir Crit Care Med. 2005;171(9):1040-47.

40. Richeldi L, Costabel U, Selman M, et al. Efficacy of a tyrosine kinase inhibitor in idiopathic pulmonary fibrosis. N Engl J Med. 2011;365(12):1079-87.

41. InterMune. Manufacturer's submission to NICE: Pirfenidone for the treatment of idiopathic pulmonary fibrosis. December 2011. Available at: https://www.nice.org.uk/guidance/TA282/documents/idiopathic-pulmonaryfibrosis-pirfenidone-intermune2. Accessed March 1, 2017.

42. Cottin V, Li H, Luppi F, et al. Effect of baseline corticosteroid medication on reduction in FVC decline with nintedanib. Eur Respir J. 2015;46(Suppl 59):OA4498.

43. du Bois RM, Weycker D, Albera C, et al. Forced vital capacity in patients with idiopathic pulmonary fibrosis: test properties and minimal clinically important difference. Am J Respir Crit Care Med. 2011;184(12):1382-89.

44. Noble PW, Albera C, Bradford WZ, et al. Analysis of pooled data from three phase 3, multinational, randomized, double-blind, placebo controlled trials evaluating pirfenidone in patients with idiopathic pulmonary fibrosis. Am J Respir Crit Care Med. 2014;189.

45. Deeks JJ, Altman DG, Bradburn MJ. Statistical methods for examining heterogeneity and combining results from several studies in meta-analysis. In: Egger M, Davey Smith G, Altman DG, eds. Systematic Reviews in Health Care: Meta-Analysis in Context. 2nd ed. London: BMJ Publishing Group; 2008:285-312.

46. Cochrane Collaboration. Cochrane handbook for systematic reviews of interventions. March 2011. Available at: http://handbook.cochrane.org/. Accessed February 9, 2017.

47. Ades AE, Lu G, Dias S, Mayo-Wilson E, Kounali D. Simultaneous synthesis of treatment effects and mapping to a common scale: an alternative to standardisation. Res Synth Methods. 2015;6(1):96-107.

48. Salanti G. Indirect and mixed-treatment comparison, network, or multiple-treatments meta-analysis: many names, many benefits, many concerns for the next generation evidence synthesis tool. Res Synth Methods. 2012;3(2):80-97. 